Full Paper: The synthesis and spectroscopic characterization of three polymeric peroxides of styrene monomers with substituents in the para position are discussed. NMR spectroscopy revealed the alternating copolymer structure with labile peroxy bonds $(-\mathrm{O}-\mathrm{O}-)$ in their main chain. The thermal reactivity of the polymers was studied by differential scanning calorimetry and thermogravimetry. The measured heat of degradation of these polymers is nearly the same as that of poly(styrene peroxide). The mechanism of the primary exothermic degradation has been substantiated by thermochemical calculations. The chain dynamics studies of these polyperoxides in terms of ${ }^{13} \mathrm{C}$ spin-lattice relaxation time $\left(T_{1}\right)$ have been carried out to understand their main chain flexibility. The temperature dependence of correlation time has been utilized for the determination of the activation energy for the overall segmental motion and internal group rotation. Their flexibil- ity in terms of glass transition temperature $\left(T_{\mathrm{g}}\right)$ have been examined. The flexibility trend observed in solution parallels that in the bulk.

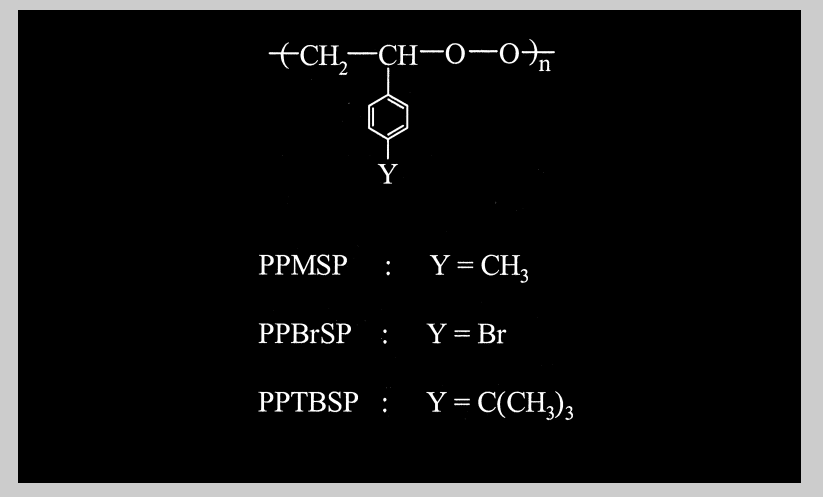

\title{
para-Substituted Poly(styrene peroxide)s: Synthesis, Characterization, Thermal Reactivities, and Chain Dynamics Studies in Solution
}

\author{
Priyadarsi De, D. N. Sathyanarayana* \\ Department of Inorganic and Physical Chemistry, Indian Institute of Science, Bangalore 560012, India \\ Fax:+91-080-3600683/3601552; E-mail: dns@ipc.iisc.ernet.in
}

Keywords: copolymerization; kinetics; NMR; polystyrene; transitions

\section{Introduction}

In 1977, Cais and Bovey reported a study of the chain flexibility and molecular dynamics of poly(styrene peroxide) (PSP). ${ }^{[1]}$ Polyperoxides had previously received attention only with regard to their intermediacy in the inhibition by oxygen of vinyl polymerization. ${ }^{[2,3]}$ Recently, studies on polymeric peroxides have been successful in providing a thermochemical basis for the unusual exothermic thermal degradation of these polymers. ${ }^{[4,5]}$ It has resulted in detecting a unique phenomenon of autopyrolysis in PSP, which has made it a candidate for specialized fuels of the future. ${ }^{[6]}$ The property of autopyrolysis exhibited by these polymers is due to their highly exothermic heats of degradation. Apart from this their technological importance as polymeric thermal ${ }^{[7]}$ and photo-initiators ${ }^{[8]}$ for vinyl monomers to synthesize homopolymers and block copolymers, and their applications as curators in coating and molding are well known. ${ }^{[9]}$
An evaluation of the heats of degradation of different polymeric peroxides is difficult for lack of data. The number of polyperoxides reported so far is only about two dozen, ${ }^{[10]}$ and except for very few, they have hardly been characterized. In view of their potential as highly exothermically degrading materials it is desirable to study polyperoxides. By a comparison of the available heat of degradation of $\mathrm{PSP}^{[4]}$ and poly(methyl methacrylate peroxide) (PMMAP), ${ }^{[5]}$ (the former being higher) it was of interest to synthesize new polyperoxides from aromatic monomers. Hence para-substituted styrenes were chosen as monomers for the preparation of polyperoxides.

Studies on the dynamics of polymer chains have attracted considerable interest because chain dynamics play an important role in determining the macroscopic properties of the polymeric systems. Among the various techniques employed for the study of chain dynamics, nuclear magnetic resonance has proved to be a powerful 
tool since it selectively allows detailed analysis of the motions of the different components of the polymer chain, at the atomic level. For example, backbone and side group motions or the motion of the different components of a copolymer can be clearly differentiated. ${ }^{[11,12]}$ Comparative studies of chain flexibility and molecular dynamics among a class of polymers will be very useful in understanding the physical properties and processability of the polymers. ${ }^{[13]}$ This type of study is rather rare in weak link polymers. Because segmental motions determine the spin-lattice relaxation in reasonably dilute solutions, a comparison of $T_{1}$ values provides a measure of the relative barriers to conformational transitions. Some insight into the general steric interactions prevalent in polymer structures may be obtained as they affect the transitions between the conformational states. Such studies have customarily been divided into two regimes: polymer solutions, in which chain motions are relatively fast, and polymers in the solid state, where motional freedom may cover several orders of magnitude. Studies on the chain dynamics in dilute solutions have the advantage that it is possible to focus on the internal motions of a single chain since the effect of inter-chain interactions are minimized. ${ }^{[14]}$

In this paper, we present studies on the synthesis, characterization, thermal reactivity, and comparative chain dynamics of three polyperoxides, namely poly ( $p$-methylstyrene peroxide) (PPMSP), poly( $p$-bromostyrene peroxide) (PPBrSP) and poly(p-tert-butylstyrene peroxide) (PPTBSP) having the following general structure:<smiles>[Y]c1ccc(CCC)cc1</smiles>

$$
\begin{array}{lll}
\text { PPMSP } & : \quad \mathrm{Y}=\mathrm{CH}_{3} \\
\text { PPBrSP }: & \mathrm{Y}=\mathrm{Br} \\
\text { PPTBSP } & : \quad \mathrm{Y}=\mathrm{C}\left(\mathrm{CH}_{3}\right)_{3}
\end{array}
$$

Dulog et al. reported the synthesis of PPMSP and PPBrSP but their spectral characterization have not been made. ${ }^{[15]}$ Both PPTBSP and PPBrSP are powdery materials, thus they are easier to handle compared to the PPMSP and PSP, which are sticky semisolids under ambient conditions.

\section{Experimental Part}

\section{Materials}

p-Methylstyrene (PMS) (Lancaster, England), p-bromostyrene (PBrS) (Aldrich, USA) and p-tert-butylstyrene (PTBS) (Lancaster, England) were freed from inhibitor by washing with $5 \% \mathrm{NaOH}$ and then with water several times. After drying over anhydrous $\mathrm{Na}_{2} \mathrm{SO}_{4}$, they were distilled under reduced pressure. 2,2'-Azobis(isobutyronitrile) (AIBN) (Koch-Light Laboratories, England) was recrystallized twice from methanol. The oxygen used was of high purity. The solvents, petroleum ether (boiling range, $60-80^{\circ} \mathrm{C}$ ), benzene, and chloroform were purified by standard procedures.

\section{Characterization Techniques}

The FT-IR spectrum was recorded on a Bruker Equinox 55 FT-IR spectrometer. The $200-\mathrm{MHz}{ }^{1} \mathrm{H}$ NMR spectra were recorded on a Bruker AC-F 200 FT-NMR spectrometer in $\mathrm{CDCl}_{3}$. The chemical shifts were assigned with respect to tetramethylsilane. The ${ }^{13} \mathrm{C}-\mathrm{NMR}$ spectra were measured in the same spectrometer using $\mathrm{CH}_{2} \mathrm{Cl}_{2}$ as solvent $\left(\mathrm{D}_{2} \mathrm{O}\right.$ external lock). The molecular weight of the polyperoxides were obtained using a Waters ALC/GPC 224 instrument with tetrahydrofuran as a mobile phase at $30^{\circ} \mathrm{C}$ using polystyrene as the standard.

The thermal analyses were done using a Perkin-Elmer DSC-2C differential scanning calorimeter (DSC) under nitrogen atmosphere at heating rates of 5, 10, 20, 40 and $80^{\circ} \mathrm{C} \cdot \mathrm{min}^{-1}$ with the samples of $1-5 \mathrm{mg}$. The thermogravimetric analysis (TGA) was accomplished on a Mettler Toledo TGA 850 instrument under nitrogen atmosphere at a heating rate of $10^{\circ} \mathrm{C} \cdot \mathrm{min}^{-1}$ with sample weights of 1 $10 \mathrm{mg}$.

The ${ }^{13} \mathrm{C}$ nuclear magnetic resonance relaxation experiments were carried out on a Bruker AMX 400 spectrometer operating at $100.6 \mathrm{MHz}$ for the ${ }^{13} \mathrm{C}$ nucleus. The sample temperature was regulated to $\pm 1 \mathrm{~K}$. Spin-lattice relaxation times $\left(T_{1}\right)$ were measured by the standard inversion recovery $(180$ $\tau-90-T)$ pulse sequence, with a $T$ of at least five times the longest $T_{1}$ of interest. The polymer solutions were not deoxygenated. The measured $T_{1}$ values are accurate to within $10 \%$.

\section{Computational Methods}

The well-documented commercial software packages Insight $\mathrm{II}^{\circledR}$ and the semi-empirical program package Ampac/Mopac (version 6.0) from Biosym Technologies ${ }^{[16]}$ have been used to calculate the heats of formation. The Insight $\mathrm{II}^{\circledR}$ code assigns an empirical potential energy function to each atom from the central valence force field depending on the element type and the nature of the chemical bond. Further, this code has been benchmarked for numerous other molecular systems and its accuracy documented in the literature. ${ }^{[16]}$ The heats of formation $\left(\Delta H_{\mathrm{f}}^{0}\right)$ were computed using semi-empirical methods. The geometry of all the compounds were fully optimized using AM1 Hamiltonian. ${ }^{[17,18]}$

\section{Polymerizations}

The polymeric peroxides were prepared using benzene solutions of the monomer and $\operatorname{AIBN}\left(0.02 \mathrm{~mol} \cdot \mathrm{L}^{-1}\right)$ in a Parr reactor equipped with stirrer (Parr Instrument Co., USA) and pressurized to $100 \mathrm{psi}$ with oxygen. The polymerization was carried out at $50 \pm 0.5^{\circ} \mathrm{C}$ with mechanical stirring. Polyperoxide was separated from the reaction mixture by precipitating it with petroleum ether. They were isolated and purified 
by repeated precipitation from benzene solution followed by the removal of the solvent by vacuum drying. It may be noted that vinyl polyperoxides, unlike acid polyperoxides, are quite safe to handle. Unlike simple organic peroxides like benzoyl peroxide, the vinyl polyperoxides are not shock sensitive, but they should be stored in the dark and in a refrigerator to minimize degradation.

\section{Results and Discussion}

Details regarding the initial monomer concentration, reaction time, yield, molecular weight and polydispersity index (PD-I) of polyperoxides are presented in Table 1. The polyperoxides have low molecular weight due to various chain transfer reactions occurring during oxygen copolymerization. ${ }^{[19]}$ The ${ }^{1} \mathrm{H}-$ and ${ }^{13} \mathrm{C}-\mathrm{NMR}$ spectra (peaks - Table 2) reveal the formation of alternating copolymer of vinyl monomer and oxygen. No homopolymer impurities could be detected from the NMR spectra.

The IR spectrum shows absorptions characteristic of the repeat units of the polymer given in Table 2 . The weak broad absorption at $3450-3600 \mathrm{~cm}^{-1}$ is observed due to the hydroxyl and hydroperoxide end groups. The formation of these end groups via various chain transfer mechanisms has been reported in the literature. ${ }^{[20,21]}$ The ${ }^{1} \mathrm{H}-\mathrm{NMR}$ spectra show signals corresponding to methy-

Table 1. Experimental data for the oxidative polymerization initiated by AIBN at $50^{\circ} \mathrm{C}$.

\begin{tabular}{|c|c|c|c|c|c|}
\hline Polymer & $\begin{array}{c}\begin{array}{c}\text { Monomer } \\
\text { conc. }\end{array} \\
\times 10^{3} \mathrm{~mol} \cdot \mathrm{L}^{-1}\end{array}$ & $\begin{array}{l}\text { Reaction } \\
\frac{\text { time }}{\mathrm{h}}\end{array}$ & $\frac{\text { Yield }}{\text { wt.- } \%}$ & $\begin{array}{c}\text { Molecular } \\
\text { weight }\end{array}$ & PD-I \\
\hline & 1.64 & 48 & 21 & 5190 & 1.7 \\
\hline PPBrSP & 1.64 & 48 & 26 & 4030 & 1.3 \\
\hline PPTBSP & 1.64 & 60 & 17 & 5360 & 1.6 \\
\hline
\end{tabular}

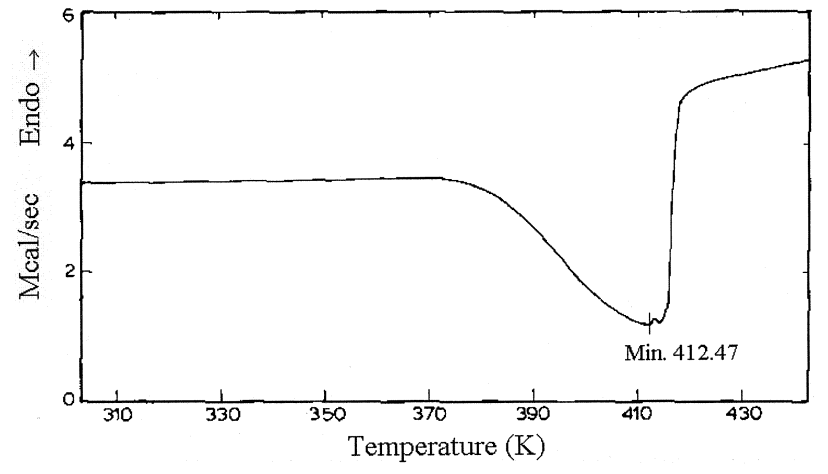

Figure 1. DSC thermogram of PPMSP at a heating rate of $10^{\circ} \mathrm{C} \cdot \mathrm{min}^{-1}$.

lene and methine protons shifted downfield due to two oxygen atoms directly bonded to it. For the same reason ${ }^{13} \mathrm{C}$-NMR spectra also show considerable downfield shift for the backbone carbon atoms. The polyperoxides show a very weak peak around $9.75 \mathrm{ppm}$ in ${ }^{1} \mathrm{H} \mathrm{NMR}$ and at $170 \mathrm{ppm}$ in ${ }^{13} \mathrm{C}$ NMR due to the $\mathrm{O}=\mathrm{CH}-$ group present as chain ends.

For the polymers, DSC studies reveal a highly exothermic degradation. A typical DSC thermogram of PPMSP is given in Figure 1. The enthalpy of degradation, $\Delta H_{\mathrm{d}}^{0}$ calculated from the mean area under the exotherm at various heating rates is listed in Table 3 , after applying the correction for the heat of vaporization of formaldehyde. The $\Delta H_{\mathrm{v}}^{0}$ for formaldehyde is reported to be $5.90 \mathrm{kcal}$. $\mathrm{mol}^{-1}{ }^{[22]}$ The $\Delta H_{\mathrm{f}}^{0}$ of the compounds studied here in their optimized structure are listed in Table 4.

A Kissinger plot ${ }^{[23]}$ of $\ln \phi / T_{\mathrm{m}}{ }^{2}$ against $1 / T_{\mathrm{m}}$, where $\phi$ is the heating rate and $T_{\mathrm{m}}(\mathrm{K})$, the peak temperature in the DSC thermogram is given in Figure 2 for all the three polyperoxides. The slope of this plot gives the activation energy for the degradation process $\left(E_{\mathrm{d}}\right)$. The $E_{\mathrm{d}}$ values

Table 2. Spectroscopic data of the polyperoxides.

\begin{tabular}{|c|c|c|c|c|c|}
\hline \multicolumn{2}{|c|}{ Infrared spectra } & \multicolumn{2}{|c|}{${ }^{1} \mathrm{H}$ NMR } & \multicolumn{2}{|c|}{${ }^{13} \mathrm{C}$ NMR } \\
\hline Assignment & Wavenumber & Assignment & $\delta$ & Assignment & $\delta$ \\
\hline \multicolumn{6}{|l|}{ PPMSP } \\
\hline$v_{\mathrm{C}-}$ & $2870-3027$ & $-\mathrm{CH}_{3}$ & 2.28 & $-\mathrm{CH}_{3}$ & 20.88 \\
\hline$v_{\mathrm{O}-}$ & 1030 & $-\mathrm{OCH}_{2}$ & 4.02 & $-\mathrm{OCH}_{2}$ & 75.67 \\
\hline$v_{\mathrm{C}-}$ & 1107 & $-\mathrm{OCH}$ & 5.27 & $-\mathrm{OCH}$ & 82.54 \\
\hline & & $\mathrm{Ar}-\mathrm{H}$ & $7.05-7.25$ & $\mathrm{Ar}-\mathrm{C}$ & $127-138.1$ \\
\hline \multicolumn{6}{|l|}{ PPBrSP } \\
\hline$v_{\mathrm{C}-}$ & $2872-3048$ & $-\mathrm{OCH}_{2}$ & 4.03 & $-\mathrm{OCH}_{2}$ & 75.4 \\
\hline$v_{\mathrm{O}-}$ & 1010 & $-\mathrm{OCH}$ & 5.24 & $-\mathrm{OCH}$ & 82.1 \\
\hline$v_{\mathrm{C}-}$ & 1075 & $\mathrm{Ar}-\mathrm{H}$ & $7.08-7.40$ & $\mathrm{Ar}-\mathrm{C}$ & $122-136.5$ \\
\hline \multicolumn{6}{|l|}{ PPTBSP } \\
\hline$v_{\mathrm{C}-}$ & $2867-2970$ & $-\mathrm{CH}_{3}$ & $1.25-1.36$ & $-\mathrm{CH}_{3}$ & 31.1 \\
\hline$v_{\mathrm{O}-}$ & 1017 & $-\mathrm{OCH}_{2}$ & 4.06 & $-\mathrm{C}\left(\mathrm{CH}_{3}\right)_{3}$ & 34.5 \\
\hline$v_{\mathrm{C}-}$ & 1108 & $-\mathrm{OCH}$ & 5.31 & $-\mathrm{OCH}_{2}$ & 75.7 \\
\hline & & $\mathrm{Ar}-\mathrm{H}$ & $7.16-7.27$ & $-\mathrm{OCH}$ & 82.5 \\
\hline & & & & $\mathrm{Ar}-\mathrm{C}$ & $125.3-151.3$ \\
\hline
\end{tabular}


Table 3. DSC data for the polyperoxides investigated.

\begin{tabular}{|c|c|c|c|}
\hline Polymer & $\frac{\Delta H_{\mathrm{d}}^{0}}{\mathrm{kcal} \cdot \mathrm{mol}^{-1}}$ & $\frac{E_{\mathrm{d}}}{\mathrm{kcal} \cdot \mathrm{mol}^{-1}}$ & $\frac{T_{\mathrm{g}}}{{ }^{\circ} \mathrm{C}}$ \\
\hline PSP & $-50^{[6]}$ & $38.2^{[7]}$ & -3.7 \\
\hline PPMSP & -49.4 & 39.0 & 4.6 \\
\hline PPBrSP & -50.0 & - & 9.6 \\
\hline PPTBSP & -51.3 & 43.7 & 19.9 \\
\hline
\end{tabular}

Table 4. Thermochemical data.

\begin{tabular}{|c|c|c|}
\hline \multirow[b]{2}{*}{ Compound } & \multicolumn{2}{|c|}{$\Delta H_{\mathrm{f}}^{0}$} \\
\hline & Value & Ref. \\
\hline PMS & 31.0 & this work \\
\hline $\mathrm{PBrS}$ & 43.4 & this work \\
\hline PTBS & 20.2 & this work \\
\hline Formaldehyde (g) & -27.7 & {$[22,24]$} \\
\hline$p$-methylbenzaldehyde & -16.8 & this work \\
\hline$p$-bromobenzaldehyde & -3.5 & this work \\
\hline p-tert-butylbenzaldehyde & -27.6 & this work \\
\hline PPMSP & 13.9 & this work \\
\hline PPBrSP & 26.3 & this work \\
\hline PPTBSP & 3.1 & this work \\
\hline
\end{tabular}

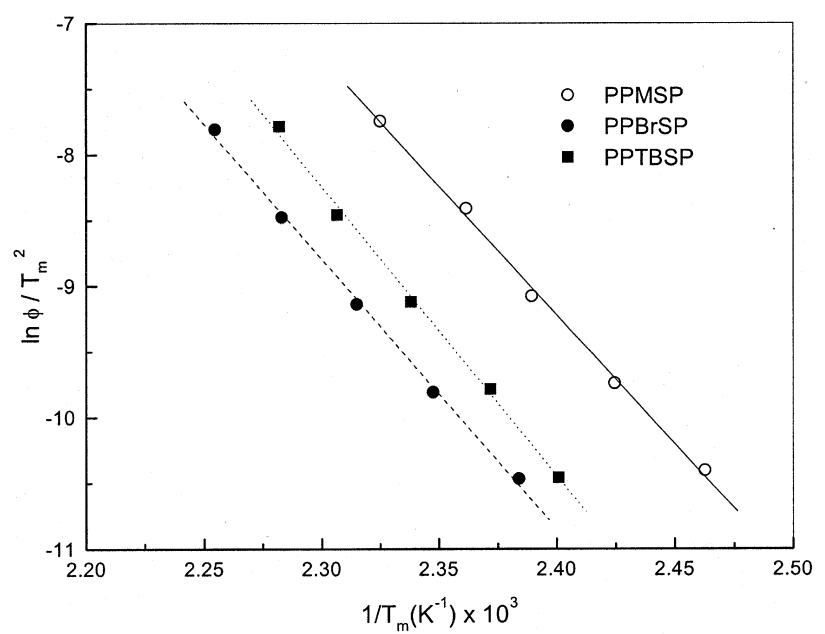

Figure 2. Kissinger plot of $\ln \phi / T_{\mathrm{m}}^{2}$ versus $1 / T_{\mathrm{m}}$, for PPMSP (o), $\operatorname{PPBrSP}(\bullet)$ and PPTBSP $(\bullet)$.

were found to lie between $39-44 \pm 2 \mathrm{kcal} \cdot \mathrm{mol}^{-1}$, (Table 3 ) which is comparable to the dissociation energy of the $\mathrm{O}-\mathrm{O}$ bond, $32 \mathrm{kcal} \cdot \mathrm{mol}^{-1}$. ${ }^{[25,26]}$ This, as well as the symmetry of the DSC thermogram (Figure 1), suggests that the degradation of the polymers is a single-step process, which is initiated by the scission of the $\mathrm{O}-\mathrm{O}$ bond. A single-step weight loss in the thermogram curve (Figure 3) supports this inference. The thermal stability of the three polyperoxides could be compared from the $E_{\mathrm{d}}$ values: the lower the $E_{\mathrm{d}}$ values, the higher is the rate of thermal degradation. On the basis of the degradation product analysis and the $E_{\mathrm{d}}$ values for the degradation process (corresponding to the cleavage of the $\mathrm{O}-\mathrm{O}$ bond), a radical chain scission

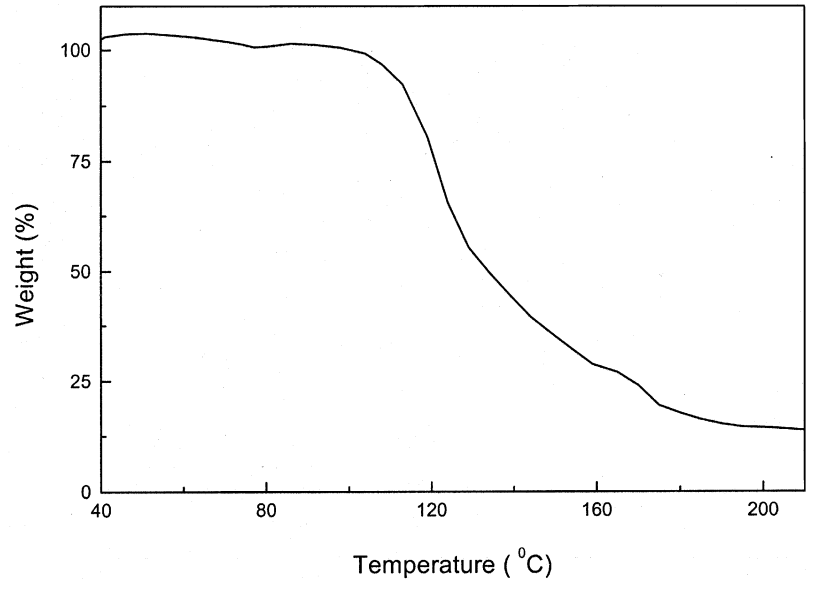

Figure 3. TGA curve of PPMSP.

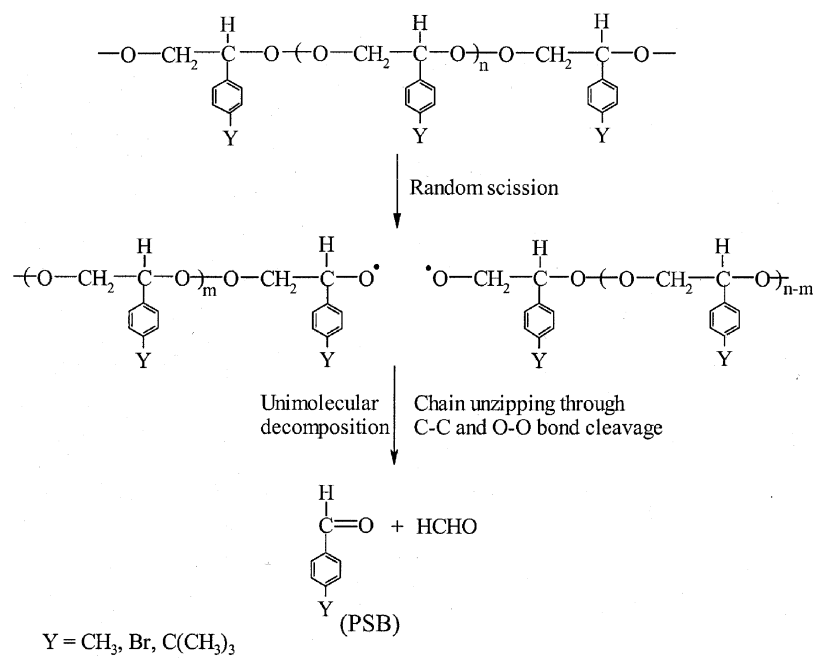

Scheme 1.

mechanism, similar to that for PSP, ${ }^{[27]}$ could be proposed for the degradation (Scheme 1).

Small amounts of products other than formaldehyde and $p$-substituted benzaldehyde (PSB), could be formed via disproportionation, which is also operative in PSP. ${ }^{[27]}$ The above mechanism indicates that the exotherm observed in the DSC is due to the primary degradation of the polymer. This finds support from the thermochemical calculations. $^{[4]}$

In order to calculate the heat of degradation $\left(\Delta H_{\mathrm{d}}^{0}\right)$, the heat of formation $\left(\Delta H_{\mathrm{f}}^{0}\right)$ of the corresponding polyperoxide should be known. It can be evaluated from the heat of polymerization $\left(\Delta H_{\mathrm{p}}^{0}\right)$.

Polyperoxide is formed by the reaction of $\mathrm{O}_{2}$ with the monomer (Scheme 2).

This process involves the scission of one $\mathrm{C}=\mathrm{C}$ and one $\mathrm{O}=\mathrm{O}$ bond and the formation of one $\mathrm{O}-\mathrm{O}$, one $\mathrm{C}-\mathrm{C}$, and two $\mathrm{C}-\mathrm{O}$ bonds. Using bond energy data from the literature, ${ }^{[25,26]}$ the calculated value of $\Delta H_{\mathrm{P}}^{0}$ is 
<smiles>[Y]c1ccc(C=C)cc1CCCC(C)COOO</smiles>

Scheme 2.

$20.9 \mathrm{kcal} \cdot \mathrm{mol}^{-1}$. However, $\Delta H_{\mathrm{P}}^{0}$ is also dependent upon the structural factors. ${ }^{[4]}$ For example, in vinyl polymerization, the cleavage of one $\mathrm{C}=\mathrm{C}$ bond in the monomer leads to the formation of two $\mathrm{C}-\mathrm{C}$ bonds in the polymer and the heat evolved in the process is $19.8 \mathrm{kcal} \cdot \mathrm{mol}^{-1}$, as compared to the experimental $\Delta H_{\mathrm{P}}^{0}$ value of $16 \mathrm{kcal} \cdot \mathrm{mol}^{-1}$ for $\operatorname{poly}(p \text {-chlorostyrene })^{[28]}$ giving a difference of $3.8 \mathrm{kcal} \cdot \mathrm{mol}^{-1}$. Taking into consideration the correction due to structural factors, an average $\Delta H_{\mathrm{P}}^{0}$ value was taken as $17.1 \mathrm{kcal} \cdot \mathrm{mol}^{-1}$ for all the three polyperoxides investigated. Using this value and the $\Delta H_{\mathrm{f}}^{0}$ for the monomer, the $\Delta H_{\mathrm{f}}^{0}$ of the polyperoxides were calculated and are given in Table 4 . The $\Delta H_{\mathrm{d}}^{0}$ for polyperoxides (PP) were calculated by two different procedures.

1) Using $\Delta H_{\mathrm{f}}^{0}$, the heat change during the above degradation process was calculated using the expression $\Delta H_{\mathrm{f}}^{0}$ $(\mathrm{PP}) \rightarrow \Delta H_{\mathrm{f}}^{0}(\mathrm{PSB})+\Delta H_{\mathrm{f}}^{0}\left(\mathrm{CH}_{2} \mathrm{O}\right)+\Delta H_{\mathrm{d}}^{0}$

It was found to be $-52.5,-51.6$ and $-52.5 \mathrm{kcal} \cdot \mathrm{mol}^{-1}$ for PPMSP, PPBrSP and PPTBSP respectively, after applying correction for the heat of vaporization.

2) The value of $\Delta H_{\mathrm{d}}^{0}$ was calculated from the bond dissociation energies. During the process of polyperoxide degradation, one $\mathrm{C}-\mathrm{C}$ and one $\mathrm{O}-\mathrm{O}$ bonds are broken while two $\mathrm{C}-\mathrm{O}$ bonds are converted to two $\mathrm{C}=\mathrm{O}$ bonds, and formaldehyde gets vaporized. The calculated enthalpy change $\left(\Delta H_{\mathrm{d}}^{0}\right)$ for this process is $-50.3 \mathrm{kcal} \cdot \mathrm{mol}^{-1}$.

Based on the $\Delta H_{\mathrm{d}}^{0}$ values calculated by the two methods, the mean value of $\Delta H_{\mathrm{d}}^{0}$ of $-51.4,-50.95$ and $-51.4 \mathrm{kcal} \cdot-$ $\mathrm{mol}^{-1}$ was obtained for PPMSP, PPBrSP and PPTBSP respectively. The calculated values of $\Delta H_{\mathrm{d}}^{0}$ for the polyperoxides suggest that the degradation process should be exothermic. The experimental $\Delta H_{\mathrm{d}}^{0}$ for the polyperoxide is comparable with that predicted theoretically from $\Delta H_{\mathrm{f}}^{0}$ and bond energies. The experimentally obtained $\Delta H_{\mathrm{d}}^{0}$ values are in good agreement with those calculated thermochemically, demonstrating that the proposed mechanism of degradation seems acceptable. Small differences between the experimental and theoretical values of $\Delta H_{\mathrm{d}}^{0}$ may arise from (a) the approximation involved in the input thermochemical data, (b) occurrence of minor side reactions during the degradation and (c) lower yields of the aldehydes under the experimental conditions.

\section{Spin-Lattice Relaxation Time}

As a representative system, normal and typical FT-NMR spectra of PPMSP are given in Figure 4. Each amplitude $A(t)$ obtained from sets of such spectra was utilized to determine $T_{1}$ according $^{[29]}$ to Equation (1):

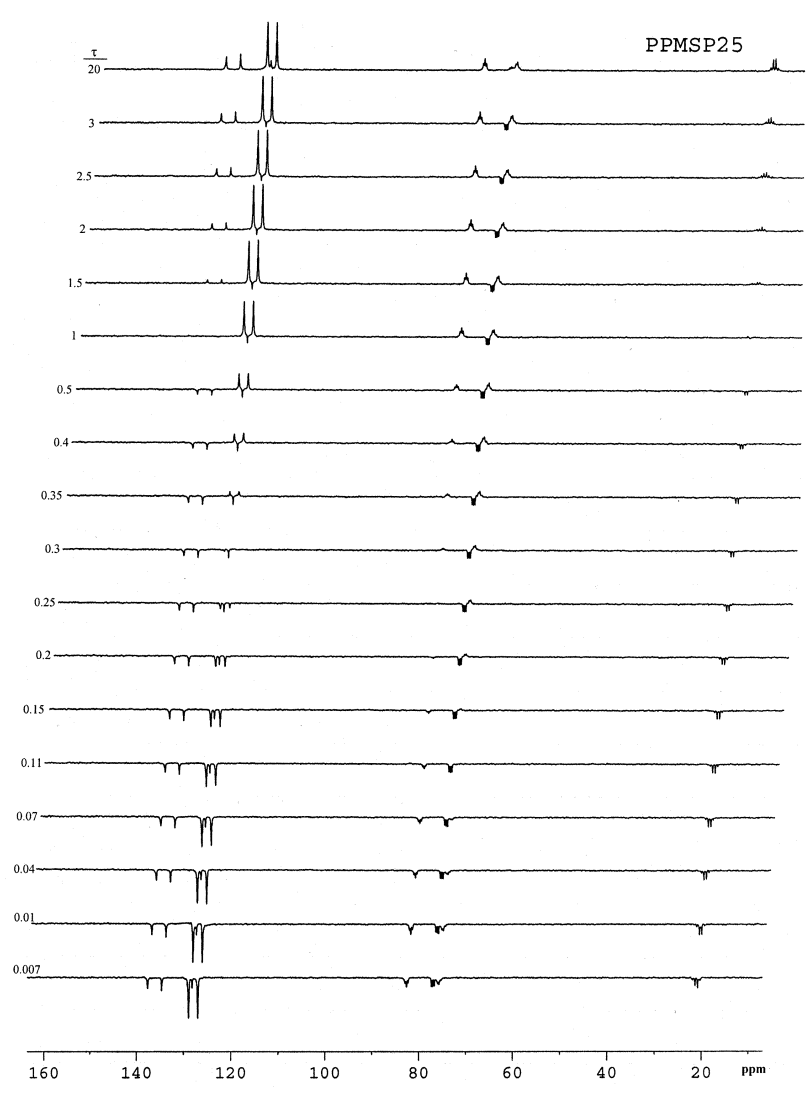

Figure 4. Proton-decoupled, natural abundance, ${ }^{13} \mathrm{C}$ FT-NMR spectra of PPMSP in 20 wt.-\% solution of $\mathrm{CDCl}_{3}$ at $100.6 \mathrm{MHz}$ and $25^{\circ} \mathrm{C}$.

$$
A(\mathrm{t})=A_{0}\left\{1-2 \exp \left(-\tau / T_{1}\right)\right\}
$$

where $A_{0}$ is the equilibrium amplitude measured in a normal FT spectrum and $\tau$ is the time interval between $180^{\circ}$ and $90^{\circ}$ pulses. The assumption of exponential recovery in Equation (1) is justified by the good linearity in the plots of $\ln \left\{\left(A_{0}-A\right) / 2 A_{0}\right\}$ versus $\tau$. The estimated values of $T_{1}$ for 20 wt.- $\%$ solution of polyperoxides at different temperature are given in Table 5, together with those for atactic polystyrene of low molecular weight from this investigation and from that of Heatley. ${ }^{[30]}$ The $2: 1$ ratio of $T_{1}$ values for the $\alpha$ - and $\beta$-carbon atoms confirm the dipole-dipole nature of the backbone carbon relaxation. This is also true for polystyrene and can be interpreted as indicating that the chain motion is effectively isotropic. ${ }^{[1]}$

The temperature dependence of $T_{1}$ is shown in Table 5 . In order to analyze the ${ }^{13} \mathrm{C}$ spin-lattice relaxation mechanism, we have assumed a purely ${ }^{13} \mathrm{C}-{ }^{1} \mathrm{H}$ dipole-dipole interaction. The spin-lattice relaxation of a ${ }^{13} \mathrm{C}$ nucleus arising from dipole-dipole interaction with bonded protons is given by:

$$
\frac{1}{N T_{1}}=\frac{1}{10} \frac{\gamma_{\mathrm{H}}^{2} \gamma_{\mathrm{C}}^{2} \hbar^{2}}{r_{\mathrm{C}-\mathrm{H}}^{6}} \chi\left(\tau_{\mathrm{C}}\right)
$$


Table 5. ${ }^{13} \mathrm{C}-T_{1}$ values for the backbone carbon atoms of the polyperoxides in $20 \mathrm{wt} . \%$ solution in $\mathrm{CDCl}_{3}$.

\begin{tabular}{lcccc}
\hline Polyperoxide & Temp. & \multicolumn{2}{c}{$T_{1}$} \\
\cline { 2 - 4 } & $\mathrm{K}$ & & \multicolumn{2}{c}{$\mathrm{S} \pm 10 \%$} \\
& & & $\mathrm{CH}_{2}$ & $\mathrm{CH}$ \\
\hline PS $^{\mathrm{a}}$ & 306 & 0.055 & 0.100 \\
PSP & 298 & 0.156 & 0.310 \\
PPMSP & 298 & 0.147 & 0.294 \\
& 288 & 0.107 & 0.216 \\
PPBrSP & 278 & 0.081 & 0.165 \\
& 298 & 0.136 & 0.273 \\
PPTBSP & 288 & 0.097 & 0.193 \\
& 278 & 0.067 & 0.143 \\
& 298 & 0.134 & 0.268 \\
& 288 & 0.095 & 0.190 \\
& 278 & 0.064 & 0.127
\end{tabular}

a) Solvent $\mathrm{CHCl}_{3}$, Molecular weight $=4000$, Conc. 22 wt.- $\%$.

where,

$$
\begin{aligned}
\chi\left(\tau_{\mathrm{C}}\right) & =\frac{\tau_{\mathrm{C}}}{1+\left(\omega_{\mathrm{H}}-\omega_{\mathrm{C}}\right)^{2} \tau_{\mathrm{C}}^{2}}+\frac{3 \tau_{\mathrm{C}}}{1+\omega_{\mathrm{C}}^{2} \tau_{\mathrm{C}}^{2}} \\
& +\frac{6 \tau_{\mathrm{C}}}{1+\left(\omega_{\mathrm{H}}+\omega_{\mathrm{C}}\right)^{2} \tau_{\mathrm{C}}^{2}}
\end{aligned}
$$

Here, $\tau_{\mathrm{C}}$ is the single correlation time expressing an exponential decay of the motional autocorrelation function and prescribing the frequency spectrum of the motion concerned; $\gamma_{\mathrm{C}}$ and $\gamma_{\mathrm{H}}$ are the magnetogyric ratios and $\omega_{\mathrm{H}}$ and $\omega_{\mathrm{C}}$ are the resonant frequencies for ${ }^{13} \mathrm{C}$ and ${ }^{1} \mathrm{H}$, respectively; $r_{\mathrm{C}-\mathrm{H}}$ is the $\mathrm{C}-\mathrm{H}$ bond length (taken here as $1.10 \AA$ ) and $N$ is the number of directly bonded protons.

In the "extreme-narrowing limit", when $\omega_{\mathrm{C}} \tau_{\mathrm{C}} \ll 1$, Equation (2) simplifies to ${ }^{[31]}$

$$
\frac{1}{N T_{1}}=\frac{1}{10} \frac{\gamma_{\mathrm{H}}^{2} \gamma_{\mathrm{C}}^{2} \hbar^{2}}{r_{\mathrm{C}-\mathrm{H}}^{6}} \tau_{\mathrm{C}}=2.03 \times 10^{10} \tau_{\mathrm{C}}
$$

For small molecules, with tumbling times of the order of picoseconds, Equation (4) holds good for dipoledipole interactions, but other mechanisms of relaxation, principally spin rotation and chemical shift anisotropy may contribute substantially. ${ }^{[32]}$ For polymers, the situation is rather different, owing to their relatively slow motions and rapid nuclear relaxation. For carbon atoms with directly bonded proton or protons, only the dipolar interactions with these protons need be considered. For quaternary and carbonyl carbon atoms dipole-dipole interactions with nearest-neighbor protons are normally dominant.

The marked temperature dependence of $T_{1}$ shows that the observations are on the high frequency side of the $T_{1}$ minimum. The data show that the polyperoxides are considerably more flexible than polystyrene, the main chain
Table 6. Activation energies for molecular motions determining the spin-lattice relaxation in the $20 \mathrm{wt} . \%$ solution in $\mathrm{CDCl}_{3}$.

\begin{tabular}{lcc}
\hline Polymer & \multicolumn{2}{c}{$\begin{array}{c}E_{\mathrm{a}} \\
\mathrm{kJ} \cdot \mathrm{mol}^{-1} \\
\text { Internal motion of } \\
\text { the side group } \\
\text { of the skeleton }\end{array}$} \\
\hline PSP & 18.2 & $25.3(\mathrm{Ph})$ \\
PPMSP & 19.9 & $28.0(\mathrm{Ph})$ \\
PPBrSP & 24.5 & $7.0(\mathrm{Me})$ \\
PPTBSP & 25.7 & $30.6(\mathrm{Ph})$ \\
& & $31.5(\mathrm{Ph})$ \\
& & $11.4(\mathrm{Me})$
\end{tabular}

$T_{1}$ values being almost twice as long under comparable conditions. Hence it is clear that the higher the $T_{1}$ values, the more flexible the backbone. ${ }^{[1]}$ Notably the $T_{1}$ values of the backbone carbon atoms as well as the side chain carbon atoms also follow this behavior, that is $T_{1}$ increases with increasing temperature. The higher value of $T_{1}$ corresponds to a short correlation time $\tau_{\mathrm{c}}$, which means that the molecular motion is rapid and the molecules have only a short memory of their previous state of motion. A good basis for comparison is ${ }^{13} \mathrm{C}-T_{1}$ values for backbone $\mathrm{CH}$ and $\mathrm{CH}_{2}$ groups, since the $\mathrm{C}-\mathrm{H}$ bond length is constant and the studies have been made under identical conditions of solvent, temperature, concentration, operating frequency, and so on.

Under "extreme-narrowing" conditions, the single correlation time motional model gives an adequate description of the chain dynamics. ${ }^{[33]}$ Accordingly, we utilize the isotropic, single- $\tau_{\mathrm{C}}$ motional model, considering two types of local motions: backbone segmental reorientation and internal motion when, ${ }^{[34,35]}$

$$
\tau_{\mathrm{C}}^{-1}=\tau_{\mathrm{R}}^{-1}+\tau_{\mathrm{I}}^{-1}
$$

Here $\tau_{\mathrm{R}}$ is the correlation time for the isotropic skeletal reorientation and $\tau_{\mathrm{I}}$ for internal rotation of the group attached to a skeleton undergoing isotropic motion.

From the temperature dependence of the correlation time, we can estimate the activation energy $E_{\mathrm{a}}$ for the motions determining spin-lattice relaxation using the rela$\operatorname{tion}^{[36]}$

$$
\tau=\tau_{0} \mathrm{e}^{E_{\mathrm{a}} / R T}
$$

where $\tau_{0}$ is the correlation time expected at infinite temperature. The activation energies for the polyperoxides estimated from the plot of $\ln \tau$ versus $1 / T$ are given in Table 6.

The activation energy for the skeletal motion of the polyperoxides is different, showing that the side chains impede chain mobility and that the larger the side chain the slower the motion, and also the higher the activation energy, which could be attributed to steric hindrance by the larger side chain spacers. On the basis of $T_{1}$ values 
and the calculated activation energies, it was found that the flexibility follows the order PSP $>$ PPMSP $>$ PPBr$\mathrm{SP}>\mathrm{PPTBSP}>\mathrm{PS}$. The small non-polar methyl group in the para-position has very little effect on the backbone mobility since the methyl group undergoes free rotation. This has been observed in the case of polystyrene derivatives with a methyl group at meta and para positions. ${ }^{[37]}$

Glass transition temperatures $\left(T_{\mathrm{g}}\right)$ for the polyperoxides under nitrogen atmosphere at a heating rate $10^{\circ} \mathrm{C} \cdot \mathrm{min}^{-1}$ are given in Table 3 . Interestingly the order of mobility deduced from $T_{1}$ values and the calculated activation energies roughly follow the order of glass transition temperature of the bulk polymers, showing that motions in solution and in the bulk glass appear to be closely related. The glass transition arises from the onset of backbone motions similar to, but perhaps of larger scale than, those determining magnetic relaxation in solution. ${ }^{[38]}$ Interchain interactions and entanglements prevalent in the solid of course greatly diminish the rate of these processes, but the frequencies are scaled proportionately.

\section{Conclusions}

The 1:1 copolymeric structure of all the three polymeric peroxides was confirmed spectroscopically for the first time. A radical chain-scission mechanism for the degradation has been proposed on the basis of the degradation products and kinetic studies. Further, as in PSP, all these polymers show a highly exothermic heat of degradation. Evidently these polyperoxides should also show auto-pyrolyzability and auto-combustibility, though no such studies have been carried out.

On the basis of activation energies for the overall tumbling and segmental motions and the $T_{\mathrm{g}}$ values, it was found that flexibility follows the order PSP $>$ PPMSP $>$ PPBrSP $>$ PPTBSP $>$ PS, that is the polyperoxide chain is more flexible than that of the hydrocarbon backbone analogue. These findings are consistent with the known low rotational barriers at the heteroatoms. ${ }^{[39]}$

Acknowledgement: We are greatly thankful to the Sophisticated Instruments Facility (SIF, IISc), for extending the facilities and in particular to Dr. G. A. Naganagowda and Mr. Chandrashekhar for recording the NMR spectra. We thank Mr. Jarali (SSCU) for recording the DSC and Mr. S. Sundarrajan for recording the GPC.

Received: April 17, 2001

Revised: August 27, 2001

Accepted: August 29, 2001

[1] R. E. Cais, F. A. Bovey, Macromolecules 1977, 10, 169.

[2] F. R. Mayo, J. Am. Chem. Soc. 1958, 80, 2465.

[3] J. Jayaseharan, K. Kishore, J. Am. Chem. Soc. 1998, 120, 825.

[4] K. Kishore, K. Ravindran, Macromolecules 1982, 15, 1638.
[5] T. Mukundan, K. Kishore, Macromolecules 1987, 20, 2382.

[6] K. Kishore, T. Mukundan, Nature 1986, 324, 130.

[7] [7a] M. K. Murthy, K. Kishore, V. K. Mohan, Macromolecules 1994, 27, 7109; [7b]) T. Mukundan, V. A. Bhanu, K. Kishore, J. Chem. Soc., Chem. Commun. 1989, 12, 780; [7c] B. Hazer, A. Kurt, Eur. Polym. J. 1995, 31, 499; [7d] M. K. Murthy, K. Kishore, Eur. Polym. J. 1997, 33, 441.

[8] K. Subramanian, K. Kishore, Polymer 1997, 38, 527.

[9] K. Subramanian, K. Kishore, Eur. Polym. J. 1997, 33, 1365.

[10] T. Mukundan, K. Kishore, Macromolecules 1989, 22, 4430.

[11] R. Sapna, D. N. Sathyanarayana, Macromolecules 1995, 28,2396

[12] R. Sapna, D. N. Sathyanarayana, Macromolecules 1996, $29,3525$.

[13] K. Ganesh, R. Latha, K. Kishore, Macromolecules 1996, 29, 5231

[14] F. A. Bovey, L. W. Jelinski, J. Phys. Chem. 1985, 89, 571.

[15] L. Dulog, Fette, Seifen, Anstrichm. 1963, 65, 108; Chem. Abstr. 1963, 59, 840b.

[16] Insight II User Guide, version 2.3.0. Biosym Technologies, San Diego, CA, 1993.

[17] M. J. S. Dewar, E. G. Zeobisch, E. F. Healy, J. J. P. Stewart, J. Am. Chem. Soc. 1985, 107, 3920.

[18] T. Clark, J. Chandrasekhar, Israel J. Chem. 1993, 33, 435.

[19] T. Mukundan, K. Kishore, Prog. Polym. Sci. 1990, 15, 475.

[20] S. Jayanthi, K. Kishore, J. Polym. Mater. 1998, 15, 5.

[21] K. Ganesh, S. Paramasivam, K. Kishore, Polym. Bull. 1996, 37, 785 .

[22] R. C. Weast, Ed., "CRC Handbook of Chemistry and Physics", 59th edition, CRC Press, Cleveland 1978.

[23] H. E. Kissinger, Anal. Chem. 1957, 29, 1702.

[24] M. Kh. Karapetyants, M. L. Karapetyants, "Thermodynamic Constants of Inorganic and Organic Compounds", translated by J. Schmorak, Ann Arbor-Humphrey Science, Ann Arbor, MI, London 1970.

[25] J. D. Roberts, M. C. Caserio, "Modern Organic Chemistry”, W. A. Benjamin: New York 1967.

[26] J. A. Deem, Ed., "Lange's Handbook of Chemistry", 11th edition, McGraw Hill, New York 1973.

[27] F. R. Mayo, A. A. Miller, J. Am. Chem. Soc. 1956, 78, 1023.

[28] H. Sawada, "Thermodynamics of Polymerization", Marcel Dekker, New York 1976, p. 42.

[29] A. Abragam, "The Principles of Nuclear Magnetism", Oxford Univ. Press, 1961.

[30] F. Heatley, A. Begum, Polymer 1976, 17, 399.

[31] K. F. Kuhlmann, Grant, R. K. Harris, J. Chem. Phys. 1970, $52,3439$.

[32] J. R. Lyerla, G. C. Levy, in: Topics in NMR Carbon-13 Spectroscopy, vol. I, G. Levy, Ed., Wiley-Interscience, New York 1974, p. 79-148.

[33] F. Heatley, M. K. Cox, Polymer 1977, 18, 225.

[34] A. Allerhand, D. Doddrell, R. Komoroski, J. Chem. Phys. 1971, 55, 189.

[35] D. Doddrell, A. Allerhand, J. Am. Chem. Soc. 1971, 93, 1558.

[36] Y. Inoue, A, Nishioka, R. Chujo, J. Polym. Sci., Polym. Phys. Ed. 1973, 11, 2237.

[37] F. Laupretre, C. Noel, L. Monnerie, J. Polym. Sci., Polym. Phys. Ed. 1977, 15, 2143.

[38] F. Heatley, Prog. Nucl. Magn. Reson. Spectrosc. 1979, 13, 47.

[39] J. R. Durig, Y. S. Li, P. Groner, J. Mol. Spectrosc. 1976, 62, 159. 